\title{
Street network structure and household activity spaces
}

\author{
Pavithra Parthasarathi \\ CDM Smith, USA
}

@SAGE

\author{
Hartwig Hochmair \\ University of Florida, USA
}

\section{David Levinson}

University of Minnesota, USA

\begin{abstract}
This research analyses the influence of street network structure on household travel patterns, as measured by activity spaces. The analysis uses street network and travel survey data from the Minneapolis - St. Paul (Twin Cities) and Miami - Ft. Lauderdale (South Florida) metropolitan areas. Various measures of street network structure are used to quantify street network structure. The activity space polygon for each household in the travel survey data set is identified by combining the destinations reached by all household members on the given travel day including the household location. Statistical regression models are then estimated for each study area to test the relationship between street network structure and household activity space. The results show that network structure has a significant influence on household travel patterns, after controlling for other non-network variables such as accessibility to jobs and shops, and car ownership.
\end{abstract}

\section{Keywords}

activity spaces, household spatial patterns, network structure, space-time framework, travel behaviour

Received August 2013; accepted March 2014

\section{Introduction}

Understanding travel demand and travel patterns (flows on networks) are among the central goals of transport planning, economics and geography, yet the influence of street network structure on travel patterns remains underexplored.
Previous research by the authors has found that network structure affects various travel behaviours (particularly vehicle

\footnotetext{
Corresponding author:

Pavithra Parthasarathi, CDM Smith, 900 Chapel Street

Suite 1450, New Haven, CT 065I0, USA.

Email: pavi0006@umn.edu
} 
distance travelled), but here we systematically relate network structure to activity space. 'Network structure' broadly refers to measures that capture the layout, arrangement and connectivity of the network (Kissling, 1969; Xie and Levinson, 2011). The 'activity space' graphically represents the places within which a group of activities are carried out by the individual or the household, subject to time constraints imposed by or on the traveller (Newsome et al., 1998). The concepts of network structure and activity space will be discussed in greater detail in the literature review section.

In this paper, we extend this research by relating street network structure to household activity spaces. The paper addresses the research question: How does the underlying street network structure affect household activity space? This question will be analysed using travel survey data from the Twin Cities and South Florida.

While network structure affects network travel time directly, it is important to note that it affects behaviour beyond its direct affect on time, which we hypothesise is partly due to its influence on the perception of time and partly due to its implication for the amount of effort (both cognitive and otherwise) that different networks engender in travellers.

Why is this understanding important? The transport system, specifically the street system, forms the primary structural element of any city. Differences in modern cities can be traced to their respective transportation systems (Marshall, 2005). Transportation is among the longest lasting artefacts of our civilisation (we still use paths first trod hundreds and thousands of years ago). Further transportation investment decisions are in general irreversible. In that regard, a good understanding of how the underlying transportation network influences travel patterns can be a valuable tool in the design of new systems.

\section{Literature review}

\section{Network structure}

The early research interest in understanding the structure of transportation networks was guided by geographers who viewed it as an essential input to regional economic development and land use (Gauthier, 1966; Haggett and Chorley, 1969; Rodrigue et al., 2006; Taaffe et al., 1996). Researchers typically used graph theory-based measures to understand the underlying network topology and geometry (Garrison and Marble, 1961; Kansky, 1963). These early approaches were, however, limited by data availability and computational power (Erath et al., 2009).

In the last few years, there has been a revival of interest in understanding the implicit structure and evolution of complex networks, not necessarily limited to transportation. This revival can be traced in part to recent advances in geographic information systems (GIS) along with easy availability of associated geospatial data (Jiang, 2007). These advances have allowed researchers to move beyond just an elementary understanding of network structure to a more cross-disciplinary approach. For example, physicists have started to look at the geography and spatial aspects of transportation networks to understand and reproduce their qualitative features (Gastner and Newman, 2006).

In the field of transportation, the focus is more on relating street network structure to travel and system performance. Patuelli et al. (2010) analysed the commuting trends in Germany using data from 439 districts in Germany for the years 1995 and 2005. The network analysis allowed the identification of the most 'open' and connected German districts and provided an understanding of the evolution of the commuting network. In particular, the connectivity analysis highlighted the decreasing centralisation and the tendency of the network to move towards a multinodal structure. 
Jenelius (2009) used the Swedish road network as a case study to understand the relationship between network structure and vulnerability. The analysis indicated that variations in road network vulnerability at a regional level could be traced to the fundamental differences in network structure. Yang et al. (2009) similarly developed an index of network structure to capture the topological vulnerability of transportation networks and identify critical links in road networks. Marshall and Garrick (2010) examined the role of street networks onroad safety outcomes using long-term crash data from 24 medium-sized Californian cities. The results indicated that measures of street network structure play an important role in influencing fatalities.

Levinson and El-Geneidy (2009) used the measure of network circuity to analyse the relationship between residential location and the journey to work. The results confirmed that the individuals do account for network topology when making location-choice decisions and that workers tend to reside in areas where the journey to work circuity is lower than random. In a recent paper, Levinson (2012) compared the variation in surface transportation network structure variables across 50 metropolitan areas in the USA. The results confirmed the variation in network structure across cities, which in turn influenced system efficiency. Daganzo (2010) examined the structure of transit networks that would allow the system to deliver service comparable with automobiles. Results showed that the more expensive the system's transit infrastructure, the more it should tilt toward the hub-andspoke concept, and that Bus Rapid Transit (BRT) competes effectively with the automobile unless a city is big and its demand low.

\section{Activity spaces}

The activity space concept is part of the space-time framework, which aids in understanding human spatial behaviour, specifically the constraints and trade-offs that exist in activity participation (Hägerstrand, 1970; Miller, 2005). Individuals are modelled as paths or trajectories in time-space, subjected to coupling, capacity and authority constraints. The transportation system constrains the area of the time-space prism, since the travel speeds and network constraints affect the time needed for travellers to get to their numerous destinations and the time remaining to participate in activities (Fan and Khattak, 2008).

Action space is defined as 'the collection of all urban locations about which the individual has information and the subjective utility or preference he associates with these locations' (Horton and Reynolds, 1971: 37). An action space is geometrically characterised by two components, namely, the spatial extent, defined by a set of locations, and a generalised surface that specifies the utility or preference level associated with each location.

An individual's activity space falls within their action space, is less extensive and encompasses the areas of their usual spatial behaviour, formally the 'subset of all urban locations within which the individual [or household] has direct contact as a result of his day-to-day activities' (Johnston, 1972: 199). The observed activity space represents the typical area over which the individual or household is likely to regularly engage in activities on a given travel day. The potential activity space, on the other hand, represents the maximal area over which the traveller could engage in activities (Cerda and ElGeneidy, 2009).

The activity space concept falls under the umbrella of activity-based approaches to travel behaviour and allows one to analyse travellers' activity patterns under various space-time constraints. For example, the concept of activity space or action space has been used to understand gender differences 
in activity-travel patterns and the corresponding implications on transportation (Dijst, 1999; Kwan, 2000). The size of the activity space explains differences in travel patterns among travellers and identifies individuals at risk of social exclusion (Schönfelder and Axhausen, 2003). In recent years, the application of activity space has been extended to other fields such as social sciences and healthcare (Sherman et al., 2005; Urry, 2003; Vallée et al., 2010).

In this paper, we use activity spaces to capture household travel. Households are a basic unit of analysis in transportation. Intra-household dynamics influence a traveller's decision in many ways, such as joint trip-making and activity participation. In addition to daily travel patterns, the household dynamics also have long-term implications for such things as job choice, residential choice and auto ownership. Understanding household travel behaviour and its implications is thus very important to researchers and policy-makers (Timmermans and Zhang, 2009).

The focus here is to identify how the street network structure affects household activity spaces after controlling for nonnetwork based variables. While aggregated travel demand as a consequence of network structure has already been examined in a few studies, the shape of the activity space has so far not been under consideration. Knowing how network characteristics affect the shape would allow to further traffic demand models.

It is important to point out that the focus of this paper is on auto modes where a smaller observed activity space is associated with better network efficiency, i.e. better access to services, goods and jobs and therefore less driving, making it more desirable. While a smaller activity space is desirable for auto modes, this is less clear for alternative transportation modes such as walking, biking and public transportation. On the one hand, a smaller activity space indicates better network efficiency. On the other hand, a larger activity space would also mean reaching a larger area. For choice riders in transit systems with different motivations, such as utilitarianism (pragmatism), dedication and convenience (Jacques et al., 2013), a larger area (usually under a given time budget, since otherwise transit would not be chosen) would also mean increased access to jobs, services, goods and other opportunities.

\section{Modelling methodology}

\section{Data}

Background: Study areas. The data for this analysis comes from two different metropolitan areas, namely the Minneapolis - St. Paul (Twin Cities) and the Miami - Ft. Lauderdale (South Florida) metropolitan areas.

The use of two study areas allows us to compare the observed effects of network structure on activity space size and shape and to assess how consistent these network effects are between both analysed areas. Both transportation networks show differences in their history and network layout (the latter will also be described in more detail in connection with Table 1).

Traffic congestion is a problem for both areas, but more so for metropolitan Miami, where a Travel Time Index (TTI) of 1.25 (47 hours of delay per auto commuter per year), is reported, as opposed to 1.21 for metropolitan Minneapolis (34 hours of delay per auto commuter per year) (Schrank et al., 2012).

Differences can also be observed in transportation mode share. The transit mode share to work is $13.10 \%$ for the City of Minneapolis and $10.85 \%$ for the City of Miami (Swanson, 2012). Bicycle commute rates from home to work are also higher for Minneapolis (3.84\%) compared with Miami $(0.43 \%)$, which can at least partially be 
Table I. Summary statistics of estimated network measures.

\begin{tabular}{|c|c|c|c|c|c|c|c|c|}
\hline \multirow[b]{2}{*}{$\begin{array}{l}\text { Independent } \\
\text { variables (Unit) }\end{array}$} & \multicolumn{4}{|c|}{ Twin Cities } & \multicolumn{4}{|c|}{ South Florida } \\
\hline & Mean & Std Dev & Min & Max & Mean & Std Dev & Min & Max \\
\hline $\begin{array}{l}\text { Proportion of } \\
\text { limited access } \\
\text { highways, \%L }\end{array}$ & 0.038 & 0.032 & 0.000 & 0.368 & 0.043 & 0.034 & 0.000 & 0.338 \\
\hline $\begin{array}{l}\text { Arterial } \\
\text { Treeness, } \phi_{\text {tree }}\end{array}$ & 0.006 & 0.015 & 0.000 & 0.496 & 0.004 & 0.027 & 0.000 & 0.464 \\
\hline $\begin{array}{l}\text { Proportion of } \\
\text { 4-degree } \\
\text { nodes, } \% N^{\circ 4}\end{array}$ & 0.314 & 0.167 & 0.045 & 0.976 & 0.235 & 0.101 & 0.066 & 0.806 \\
\hline $\mathrm{P} 2 \mathrm{~A},\left(\mathrm{~km}^{-1}\right)$ & 23.987 & 3.145 & 18.365 & 55.145 & 24.425 & 3.696 & $|8.31|$ & 49.440 \\
\hline $\begin{array}{l}\text { Street density, } \rho_{l a} \\
\left(\mathrm{~km}^{-1}\right)\end{array}$ & 19.463 & 8.780 & 3.388 & 166.660 & 14.792 & II.I77 & $1.81 \mathrm{I}$ & 214.427 \\
\hline $\begin{array}{l}\text { Number of } \\
\text { observations }\end{array}$ & \multicolumn{4}{|c|}{1998} & \multicolumn{4}{|c|}{663} \\
\hline
\end{tabular}

Note: Network measures estimated within the household activity space polygon.

attributed to worse cycling safety in Miami (6.37 deaths per 10,000 daily cyclists) compared with Minneapolis (1.05) and a larger number of on-road designated bicycle lanes and off-road multipurpose bicycle trails in Minneapolis (Swanson, 2012). Different weather conditions could also play a role (Hochmair, 2013; Smith and Kauermann, 2011). However, despite these differences in network layout and network usage, the analysis of this paper will show that the effect of network characteristics on activity spaces is relatively similar.

Travel behaviour. The data for the Minneapolis - St. Paul area are obtained from the Travel Behavior Inventory (TBI), a comprehensive one-day travel survey conducted in the Twin Cities area by the Metropolitan Council and the Minnesota Department of Transportation (MnDOT) (Metropolitan Council, 2003). The Twin Cities TBI consists of 58,345 trips undertaken by 6219 households comprised of 14,671 individuals. The data were extracted to include only those trips that originated and were destined for the Twin Cities metropolitan area, defined here as the seven counties of
Anoka, Carver, Dakota, Hennepin, Ramsey, Scott and Washington. The final extracted data set consists of 38,432 trips.

The travel behaviour data for Florida comes from the 1999 Southeast Florida Travel Survey (Florida Department of Transportation, 1999). The travel survey provides information on the one-day travel patterns of randomly selected residents in Palm Beach, Miami-Dade and Broward Counties. The survey consists of 33,082 trips undertaken by 4603 households comprised of 8873 individuals.

For the purpose of our analysis, only those trips with both the origin and destination within South Florida were considered. This provided 9402 trips with both the origin and destination located within Fort Lauderdale (Broward county) and 9334 trips where both the trip origin and destination were located within Miami (Miami-Dade county).

The survey data for the Twin Cities and Florida were downloaded from the Metropolitan Travel Survey Archive (MTSA), maintained at the University of Minnesota (Nexus Research Group, 2008). 
While the use of a short duration (1-day) survey might not capture the entire complexity in individuals' activity/travel patterns (Schönfelder and Axhausen, 2004), these surveys do provide information on the daily travel patterns such as activity locations, trip purposes and mode choice (Stopher and Wargelin, 2010). The information from the 1-day surveys has been successfully used by researchers to generate activity space polygons and to understand spatial activity and travel patterns (Cerda and El-Geneidy, 2009; Fan and Khattak, 2008).

Street networks. The street network data for the study areas (Twin Cities, South Florida) were extracted from the 2000 Census TIGER/Line files, developed and maintained by the US Census Bureau. The Topologically Integrated Geographic Encoding and Referencing (TIGER) files provide information on various features such as roads, railroads, rivers, as wells as legal and statistical geographic areas (US Census Bureau, 2008). The extracted networks for the two study areas were cleaned to include only the road features, using the Feature Class Codes (FCC) for the line segments provided in the Census TIGER/Line files.

\section{Model formulation}

This research tests the relationship between measures of street network structure and household activity space.

A stylised representation in functional form of the proposed model is provided below:

$$
S=f(N, E, X, C)
$$

where: $S$ is area $\left(\mathrm{km}^{2}\right)$ of the household activity space polygon, $N$ is measures of street network structure within the activity space, $E$ is household socioeconomic and demographic characteristics (e.g. number of workers in the household, household income), $X$ is other control variables (e.g. accessibility, job density, distance to downtown or city centre), $C$ is compactness of the household activity space, included to account for the shape of the activity space polygon.

Compactness is defined (Harding et al., 2013) as:

$$
C=\frac{P_{c}}{P_{a}}
$$

where: $P_{a}$ is perimeter of the identified activity space polygon, and $P_{c}$ is perimeter formed by a circle having the same area as the identified activity space polygon.

The compactness variable is unitless; 1 indicates that the activity space polygon is similar in shape to a circle; 0 indicates an elongated activity space polygon, closely resembling a line. The calculation of compactness accounts for the spatial aspect of the activity space polygon.

In a similar manner, a model is developed which relates network structure and compactness of the household activity space. This model can be represented as follows:

$$
C=f(N, E, X)
$$

\section{Identification of household activity space}

The first step in the analysis identifies the activity space for each household in the travel survey data set. As mentioned above, the travel survey data provide information on all trips undertaken by the individual on the travel day. The individual-level trip data was aggregated to the household level for the purpose of our analysis. For each household in the travel survey, the household location and the destinations reached by all household members on the travel day were identified. These locations were then mapped based on provided $\mathrm{X}$ and $\mathrm{Y}$ coordinates, where ESRI's ArcGIS 9.3 software suite was 


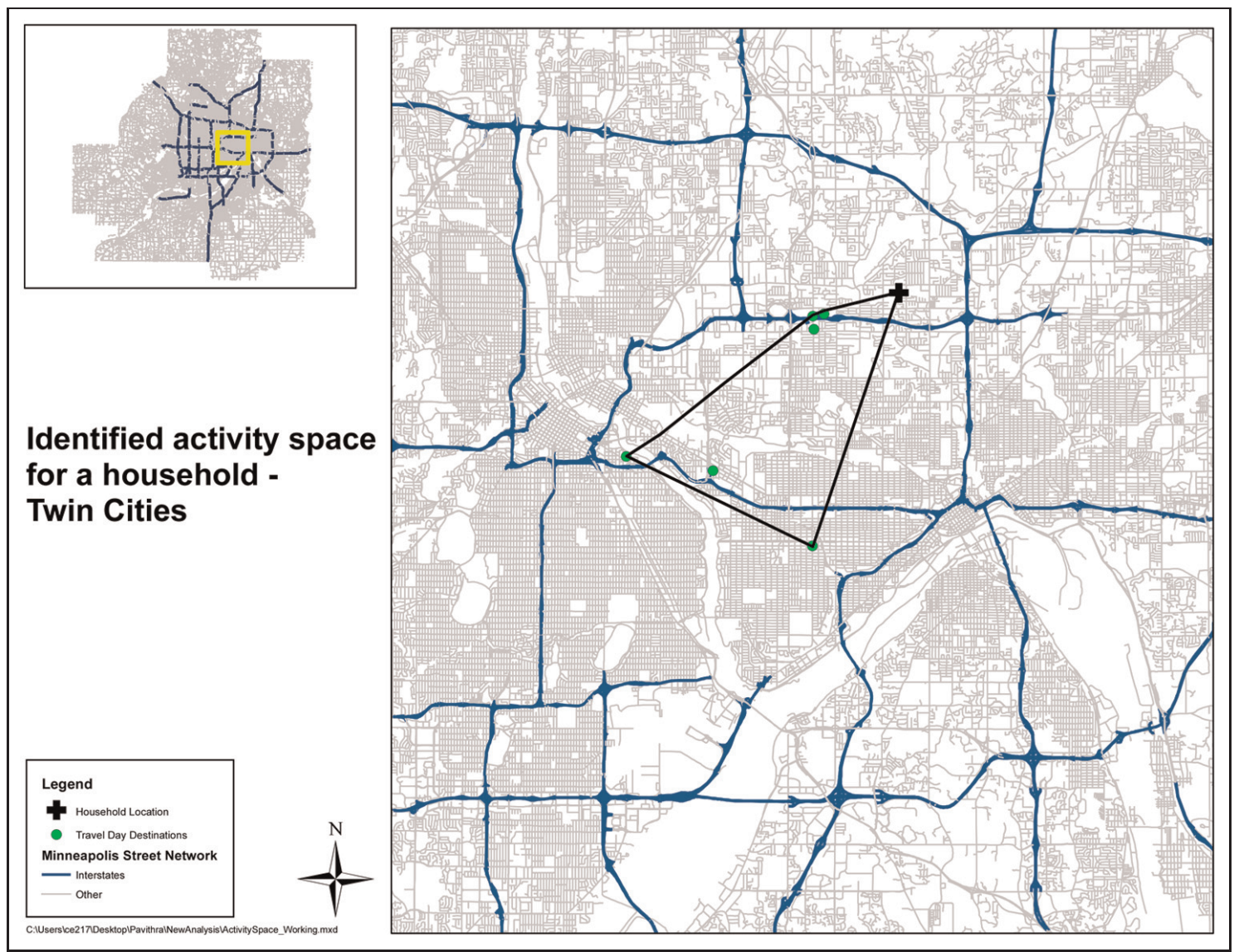

Figure I. Sample of the activity space for a surveyed household in the Twin Cities Road Network. Source: Census TIGER/line files, http://www.census.gov/geo/www/tiger/.

used. Based on these locations a household activity space polygon, i.e. the convex hull over all locations, was generated. This process was implemented on the travel survey data for both study areas. The activity space measured in this analysis represents an observed activity space, because of the use of reported travel survey data.

Figure 1 illustrates the activity space identified for one household in the Twin Cities travel survey. The + sign represents the household location and the green dots represent the destinations reached by the household members on the travel day. A convex hull over these locations was used to generate the activity space polygon for this specific household. This process of identifying the activity space polygon was repeated for all the households in both study areas. The area (in $\mathrm{km}^{2}$ ) and compactness were then estimated for each identified activity space polygon in the two study areas.

Since the focus of this research is on the quantification of street networks, only those destinations that were reached using drive alone and carpool modes were considered in our analysis. Non-auto mode share is small in each area. Census Journey-to-Work indicates an $8.6 \%$ non-auto share in the Twin Cities and a 7.5\% share in South Florida (US Census Bureau, 2010).

A minimum of three points (an origin and two destinations) was needed to generate the activity space polygon for each household. Households with no trips or just one destination on the travel day were removed from 
Table 2. Selected sociodemographic comparison of households included and excluded from the analysis.

\begin{tabular}{|c|c|c|c|c|}
\hline \multirow[b]{2}{*}{ Variable } & \multicolumn{2}{|c|}{ TWIN CITIES } & \multicolumn{2}{|l|}{ FLORIDA } \\
\hline & $\begin{array}{l}\text { Households } \\
\text { excluded }^{\mathrm{a}}\end{array}$ & $\begin{array}{l}\text { Households } \\
\text { included }^{b}\end{array}$ & $\begin{array}{l}\text { Households } \\
\text { excluded }^{\mathrm{a}}\end{array}$ & $\begin{array}{l}\text { Households } \\
\text { included }^{b}\end{array}$ \\
\hline \multicolumn{5}{|l|}{ Household income } \\
\hline Low income & $40 \%$ & $24 \%$ & $42 \%$ & $31 \%$ \\
\hline Medium income & $51 \%$ & $58 \%$ & $46 \%$ & $53 \%$ \\
\hline High income & $9 \%$ & $18 \%$ & $12 \%$ & $16 \%$ \\
\hline $\begin{array}{l}\text { Total } \\
\text { Household size }\end{array}$ & $100 \%$ & $100 \%$ & $100 \%$ & $100 \%$ \\
\hline 1 & $48 \%$ & $26 \%$ & $22 \%$ & $15 \%$ \\
\hline 2 & $32 \%$ & $35 \%$ & $36 \%$ & $33 \%$ \\
\hline 3 & $11 \%$ & $16 \%$ & $21 \%$ & $20 \%$ \\
\hline 4 & $8 \%$ & $17 \%$ & $12 \%$ & $19 \%$ \\
\hline $5+$ & $2 \%$ & $7 \%$ & $9 \%$ & $13 \%$ \\
\hline Total & $100 \%$ & $100 \%$ & $100 \%$ & $100 \%$ \\
\hline
\end{tabular}

Notes:

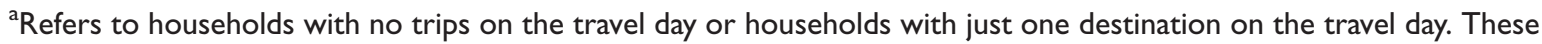
households were excluded from the analysis.

${ }^{b}$ Refers to households with a minimum of three trip ends (one origin and two destinations). These households were included in the analysis.

our analysis. The final data set consisted of 2740 households in the Twin Cities and 1021 households in Florida.

The use of a minimum of three points excludes households. However, households with at least one travel destination have been used in other related research such as in the analysis of spatial separation (Parthasarathi et al., 2012) or travel time perception (Parthasarathi et al., 2013).

A comparison of selected sociodemographic characteristics (e.g. household size, household income) between included and excluded households was conducted and summarised in Table 2. For example, consider the household income variable for the Twin Cities study area. The households included in our analysis have a higher proportion of mediumand high-income households compared with the households excluded (76\% versus $60 \%)$ from our analysis. Similarly a comparison of household size in the Twin Cities study area shows that the households included in our analysis have a larger household size compared with the households excluded from our analysis. These findings are consistent across both study areas.

\section{Estimation of network measures}

The next step in the analysis was to estimate measures of street network structure within the identified activity space polygon for each household. These network measures are broadly categorised into four main categories: hierarchy, topology, morphology and scale.

Hierarchy measures the differentiation that exists in the street network. Topology captures the connectivity and the connection patterns that exist in street network. Morphology describes the regularity, shape and fragmentation of street networks. Scale captures the supply of network in a particular area (de Smith et al., 2007; Xie and Levinson, 2007).

Table 3 summarises the various network measures that were estimated within the activity space polygon, identified for each household in the travel survey. The measures 
Table 3. Estimation of network measures.

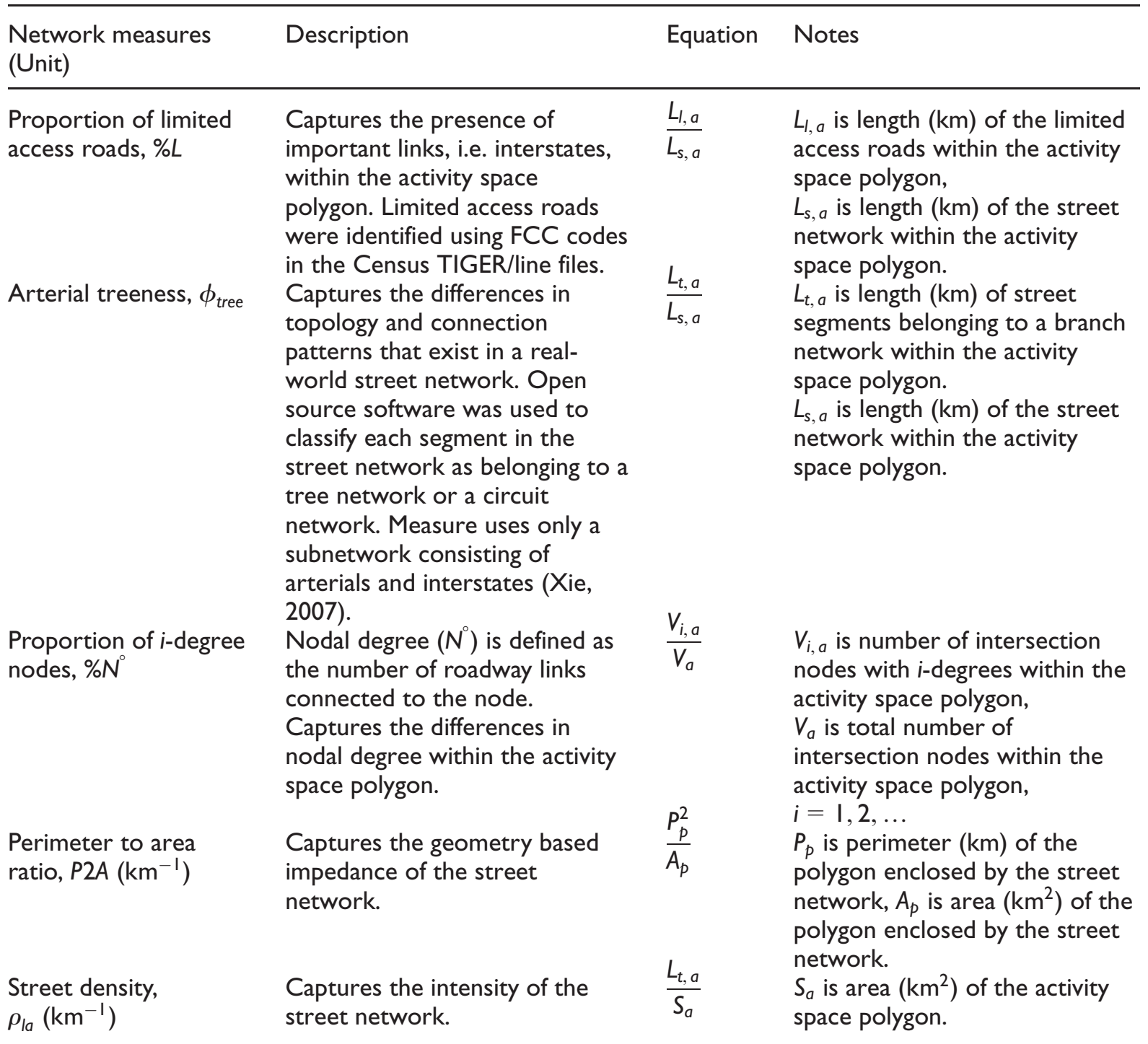

of network structure presented here were selected based on their performance in the models presented later in the paper. Other measures of network structure were also developed corresponding to the broad categories of hierarchy, topology, morphology and scale but they are not presented here owing to their insignificance in the models or the correlation with other variables. Summary statistics for the estimated network measures for the two study areas are provided in Table 1 .

\section{Control variables}

In addition to the measures of network structure, the following control variables were used in the regression models estimated later in this paper.

Accessibility measures. The accessibility data for the Twin Cities metropolitan area were obtained as part of a multiyear research effort at the University of Minnesota. This research project uses the concept of 
accessibility to understand the interaction of land use and transportation and how this interaction in turn influences the transportation system usage. Cumulative accessibility to population, employment and labour within a specified time threshold, ranging from 10 minutes to 60 minutes, was estimated for each Transportation Analysis Zone (TAZ) in the Twin Cities metropolitan area. These measures were estimated for different destinations using various modes (auto, bus, walk). The TAZ-level accessibility data from 2010 were used in this analysis (Owen and Levinson, 2012).

The cumulative opportunity accessibility measure was estimated as (Anderson et al., 2013):

$$
A_{x, i, T, m}=\sum_{j=1}^{J} O_{x, j} d\left(c_{i j, m}\right)
$$

where $A_{x, i, T, m}$ is accessibility from a zone $(i)$ to opportunities of type $(x)$ (e.g. employment, labour, shopping) at $(j)$ reachable in time $T$, by mode $(m) ; O_{x, j}$ is opportunities in zone $j$ of type $x ; c_{i j, m}$ is generalised (or real) time or cost from $i$ to $j$, by mode $m$; $d\left(c_{i j, m}\right)=1$ if $c_{i j, m}<T$ and 0 otherwise; $T$ is time threshold, indicating the time for which the number of activities that can be reached is computed. $T$ varies from 10 minutes to 60 minutes and is to capture both short and long trips. $T=20$ minutes was chosen for this analysis as it is closest to the typical mean commuting time.

The cumulative opportunity measure was used to estimate TAZ accessibility because of ease of computation and understanding. Additional details on the cumulative accessibility estimation are provided in related research (El-Geneidy and Levinson, 2006; Levinson et al., 2010). For the purposes of this analysis, the cumulative accessibility measures were merged with the Twin Cities travel survey data using the TAZ of the household as the common identifier. This
Table 4. Rotated factor loadings.

\begin{tabular}{lll}
\hline Independent variables & Factor I & Factor 2 \\
\hline$A_{\text {jobs, }, \text {, 20, auto }}$ & 0.9509 & \\
$A_{\text {jobs, }, \text {, 20, transit }}$ & 0.5970 & 0.7000 \\
$A_{\text {labor }, i, 20, \text { auto }}$ & 0.9576 & \\
$A_{\text {labor }, i, 20, \text { transit }}$ & 0.5795 & 0.7122 \\
$A_{\text {shop, i, 20, auto }}$ & 0.9347 & 0.3124 \\
$A_{\text {shop }, i, 20, \text { transit }}$ & & 0.8595 \\
$A_{\text {shop }, i, 20, \text { walk }}$ & & 0.9208
\end{tabular}

Notes:

Only loadings with absolute values greater than 0.3 presented.

Loadings represent correlations between independent variables and identified factors.

Accessibility factors measured at the TAZ of the household.

Factor I consists primarily of accessibility by auto. Factor 2 consists primarily of accessibility by transit and walk.

analysis used $A_{j o b s, i, 20, \text { auto }}, A_{j o b s, i, 20, \text { transit }}$, $A_{\text {labor, }, i, 20, \text { auto }}, A_{\text {labor, }, i, 20, \text { transit }}, \quad A_{\text {shop, }, 20, \text { auto }}$, $A_{\text {shop, }, 20, \text { transit }}$, and $A_{\text {shop, }, \text {,20, walk }}$.

The factor analysis technique was used to reduce the above-listed accessibility variables into two relevant factors. The rotated factor loadings of the accessibility variables are provided in Table 4 . These two factors were then included as independent variables in the regression models estimated for the Twin Cities metropolitan area.

Job density. The accessibility data were not available for the South Florida study area. Instead a measure of job density within the identified service area polygon was estimated for each household in the data set. The service area polygon is the area that can be reached by car on the street network within a certain time threshold, which was set to $T=20$ minutes in this analysis. The TAZs that overlap each household's service area polygon were first identified and the respective employment was summarised. This total employment was then divided by 
the total area of the TAZs overlapping the service area polygon to get a measure of job density. This variable was then used as a control variable in the regression models for South Florida, presented in Tables 7 to 9. The TAZ-level socioeconomic data (employment) for the South Florida study area was obtained from FSUTMSOnline, a web portal for transportation modelling, maintained by the System Planning Office of the Florida Department of Transportation (Florida Department of Transportation, 1999).

Distance measure. A distance measure was introduced to account for the accessibility and relative location of households with respect to the downtown or city centre. The Euclidean or straight line distance $\left(D_{C B D}\right)$ from the household location to the respective downtowns (Minneapolis and St. Paul, or Ft. Lauderdale and Miami) was then estimated using the $\mathrm{X}, \mathrm{Y}$ coordinates of the household and the $\mathrm{X}, \mathrm{Y}$ coordinates of the TAZ centroid. The distance variables were included only in the path analysis model for the prediction of compactness owing to the correlations with other independent variables. The path analysis model is presented in the Analysis section of this paper.

Sociodemographic variables. Sociodemographic variables obtained from the travel survey data for the two study areas were also used as control variables in the analyses. The variables included are income level, household size (number of workers, number of nonworkers) and auto ownership.

\section{Hypotheses}

The models identified above are operationalised with a set of specific hypotheses:
1. Aspects of network structure that increase network speed $(\% L)$ will:

Increase the activity space because of an increase in the ability to cover larger distances.

Decrease the compactness of the activity space since this facilitates long-distance travel towards job opportunities resulting in an elongated arrangement of stops.

2. Aspects of the network that simplify network legibility $\left(\% N^{\circ}\right)$ will:

Increase the activity space.

Increase compactness since they facilitate travel in more directions compared with $\mathrm{T}$ intersections. Higher percentage of 4-degree nodes indicates a grid-like network, which is more compact.

3. Aspects of network structure which decrease network speed $\left(\rho_{l a}\right)$ will:

Reduce actual trip length and the associated activity space.

Increase compactness since it provides better facilitation of travel in all directions compared with sparse road networks.

4. Aspects of network structure which increase network travel distance between fixed origins and destinations $\left(P 2 A\right.$ and $\left.\phi_{\text {tree }}\right)$ will:

Reduce the actual travel distance undertaken by travellers at those origins and the associated activity space. Travellers will respond to higher point-to-point travel times by reducing trip length (changing the point of destination vis-à-vis the point of origin).

Decrease compactness since this prevents the traveller from moving freely in all directions without significant detour. 
5. An increase in the multimodal accessibility to opportunities (jobs, shops etc.) near the household $\left(A_{x, i, T, m}\right)$ will:

Decrease the activity space. Greater opportunities near the household location will reduce the need for longer travel and thus reduce the associated activity space.

Increase compactness since opportunities are more evenly distributed in all directions around the household as opposed to low accessibility areas where longer travel towards locations of greater opportunities must be conducted.

6. An increase in distance to the downtown or city centre $\left(D_{C B D}\right)$ will:

Increase the required travel distance to jobs and thus increase the size of the activity space.

Decrease compactness since longer trips to job opportunities are required, giving a more elongated distribution of trip locations.

7. An increase in the compactness $(C)$ of the activity space will increase the activity space since it makes the polygons more circle-like.

\section{Analysis}

The estimated models are described below and Table 5 summarises the functional forms used in each of the models.

\section{Model I}

In this model, the area of the activity space was estimated as a function of only nonnetwork control variables using a linear regression model. The dependent variable (i.e. area of activity space) was included in natural $\log$ form while the independent nonnetwork variables remain in linear form. The accessibility variables were included as factors. The results of this model are presented in Table 6 .
Table 5. Functional form of estimated models.

\begin{tabular}{ll}
\hline Estimated models & Functional form \\
\hline Model I & $S=f(E, X)$ \\
Model 2 & $S=f(E, X, N)$ \\
Model 3 & $S=f(E, X, N, C)$ \\
Model 4 & $S=f(E, X, N, C) ; C=f(X, N)$
\end{tabular}

Notes:

$S$ is area $\left(\mathrm{km}^{2}\right)$ of the household activity space polygon; $N$ is measures of street network structure within the activity space; $E$ is household socioeconomic and demographic characteristics (e.g. number of workers in the household, household income); $X$ is other control variables (e.g. accessibility, job density, distance to downtown or city centre); $C$ is compactness of the household activity space, included to account for the shape of the activity space polygon.

\section{Model 2}

Here, the area of the activity space was estimated as a function of both network and non-network control variables. The model results are tabulated in Table 7.

\section{Model 3}

In this model, the observed compactness of the activity space was included as an additional independent variable in predicting the area of the activity space. The inclusion of the compactness variable was to control for the spatial aspect of the activity space polygon. Table 8 summarises the results of this model.

\section{Model 4}

This model used the path analysis technique to understand the influence of network structure on the area and compactness of activity space. Path analysis is a statistical procedure primarily used in disciplines such as sociology, political science and economics to understand causal relationships among variables (Leclair, 1981). The path analysis technique has its roots in biological sciences 
Table 6. Model I: Prediction of household spatial patterns without including measures of network structure.

$\ln ($ area of activity space)

\begin{tabular}{|c|c|c|c|c|c|c|c|}
\hline \multirow[b]{2}{*}{ Independent variables } & \multirow[b]{2}{*}{$H$} & \multicolumn{3}{|c|}{ Twin Cities } & \multicolumn{3}{|c|}{ South Florida } \\
\hline & & Coef. & $t$ & Sig. & Coef. & $t$ & Sig. \\
\hline Total vehicles in household & $+\mathrm{S}$ & 0.231 & 5.825 & $* * *$ & 0.051 & 0.712 & \\
\hline Number of workers in household & $+\mathrm{S}$ & 0.263 & 6.203 & $* * *$ & 0.092 & 1.463 & \\
\hline Medium income ${ }^{c}$ & $+S$ & 0.326 & 3.867 & $* * *$ & 0.495 & 3.547 & $* * *$ \\
\hline High Income ${ }^{c}$ & $+S$ & 0.447 & 4.158 & $* * *$ & 0.627 & 3.470 & $* * *$ \\
\hline Urban area dummy - Miami & & NA & NA & NA & 0.338 & 2.882 & $* * *$ \\
\hline Accessibility factor $\left.\right|^{\mathrm{a}}$ & $-\mathrm{S}$ & -0.343 & -10.673 & $* * *$ & NA & NA & NA \\
\hline Accessibility factor $2^{\mathrm{b}}$ & $-S$ & -0.100 & -3.083 & $* * *$ & NA & NA & NA \\
\hline Job density within activity space polygon & $-S$ & NA & NA & NA & 0.000 & -2.033 & $* *$ \\
\hline Constant & & 2.410 & 27.476 & $* * *$ & 2.660 & 12.737 & $* * *$ \\
\hline Number of observations & & 1998 & & & 663 & & \\
\hline$R$-squared & & 0.189 & & & 0.062 & & \\
\hline Adj. R-squared & & 0.186 & & & 0.053 & & \\
\hline
\end{tabular}

Notes:

* $\mathrm{p}<0.10, * * \mathrm{p}<0.05, * * * \mathrm{p}<0.01$.

${ }^{a}$ Accessibility factor I consists primarily of the accessibility to jobs, labour and shops by auto.

${ }^{b}$ Accessibility factor 2 consists primarily of the accessibility to jobs, labour and shops by transit; accessibility to shops by walk.

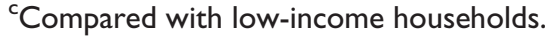

and was developed as a means of relating the correlation coefficients between variables in a multiple system to the functional relationships among them (Wright, 1934).

The statistical procedure in path analysis involves the use of standardised multiple regression equations to test the appropriateness of the causal model and to examine the comparative strength of direct and indirect relationships among variables. Causal analysis plays a very important role in the application of path analysis and it is important for the researcher to have a developed theory of causal relationships prior to applying this technique.

A path diagram is typically used to represent the hypothesised model in path analysis. The arrows in the diagram represent a causal relationship leading from the explanatory (causal) variable to the outcome (effect) variable. The explanatory variables and outcome variables are also referred to as the exogenous and endogenous variables in the model.

The exogenous variables have a cause external to the model and explain the outcomes in the model. These variables are identified by outgoing arrows in the path diagram. The endogenous variables are internal to the model and are caused by one or more variables within the model. These are identified by incoming arrows in the path diagram. The intervening endogenous variable is another variable type in the causal model. These variables are identified in the path diagram by the presence of both incoming and outgoing arrows (Lleras, 2005).

The path diagram used in this analysis is presented in Figure 3. Based on the path diagram, the network variables (e.g. percentage of limited access highways, treeness, etc.) and control variables (accessibility, income, distance to downtown, etc.) were included as 
of limited access highways is positive in both study areas but is not significant in either of the study areas. Both the accessibility factors and the job density variable have a negative influence on the activity space area, as hypothesised.

One internal inconsistency in results is the percentage of 4-degree nodes which has a significant positive influence in the Twin Cities model but contradicts the hypothesis in the South Florida model where a higher percentage of 4-degree intersections is associated with larger activity polygons. This difference between both regions could be explained by the fact that 4-degree intersections are more frequently found in grid networks of downtown areas as opposed to new developments in suburban areas, and that, opposed to Minneapolis, the downtown areas of Fort Lauderdale and Miami are located along the coast, restricting trips originating from these areas in an easterly direction. Activities of these households are therefore more located along the northsouth axis following the coastal direction, leading to more elongated and therefore smaller activity area polygons. The activity space for one household near the downtown Fort Lauderdale area is shown in Figure 2, indicating the general north-south orientation of the activity space. The remaining control variables perform as expected.

When we compare the two models presented in Tables 6 and 7, we see that the inclusion of network measures significantly improves overall model performance in both study areas. The adjusted $R^{2}$ for the Twin Cities model increases from 0.186 in the model with no independent network measures to 0.456 in the model with independent network measures. Similarly the adjusted $R^{2}$ for the South Florida model increases from 0.053 to 0.361 .

The results of Model 3, presented in Table 8, shows the effect of including activity space compactness as an independent variable in the regression analysis. The activity space compactness is significant and positive in both study areas confirming our hypothesis that an increase in the activity space compactness leads to an increase in the size of the activity space. The remaining network and control variables included in this model perform similarly to models 1 and 2 and are consistent with our hypotheses. Further the inclusion of the compactness variable improves the overall model performance in both study areas with the adjusted $R^{2}$ for the Twin Cities and South Florida model increasing to 0.530 and 0.484 , respectively. The results highlight the role of shape in explaining the size of the activity space polygon.

The results of the path analysis model are presented in Table 9. The first part of the table presents the relationship between network and control variables and activity space compactness. The second part of the table presents the relationship between network variables, control variables, compactness and the size of the activity space. The results are in line with the causal model presented in Figure 3.

The first part of Table 9 shows the influence of network measures on the compactness of the activity space. The treeness and P2A variables are highly significant and have a negative influence on the compactness of the activity space as was hypothesised. The street density variable contradicts our initial hypothesis and is highly significant and negative in both study areas. A reason might be that dense streets are in practice elongated and shaped more like a rectangle rather than a square. For example, the city blocks in Minneapolis are rectangular in shape along the north-south direction and those in St. Paul are rectangular in shape along the eastwest direction. A rectangular shaped block encourages people to travel along the long edge of the rectangle to minimise stops, thus elongating their activity space in the 
Table 8. Model 3: Prediction of household spatial patterns including measures of network structure and activity space compactness.

\begin{tabular}{|c|c|c|c|c|c|c|c|}
\hline \multirow[b]{2}{*}{ Independent variables (unit) } & \multirow[b]{2}{*}{$H$} & \multicolumn{3}{|c|}{ Twin Cities } & \multicolumn{3}{|c|}{ South Florida } \\
\hline & & Coef. & $t$ & Sig. & Coef. & $t$ & Sig. \\
\hline Total vehicles in household & $+\mathrm{S}$ & 0.101 & 3.234 & $* * *$ & 0.040 & 0.899 & \\
\hline Number of workers in household & $+\mathrm{S}$ & 0.221 & 6.503 & $* * *$ & 0.086 & 1.865 & * \\
\hline Medium income $^{d}$ & $+\mathrm{S}$ & 0.256 & 3.891 & $* * *$ & 0.368 & 3.565 & $* * *$ \\
\hline High income $^{d}$ & $+\mathrm{S}$ & 0.298 & 3.618 & $* * *$ & 0.454 & 3.407 & $* * *$ \\
\hline Urban area dummy - Miami & & & & & 0.339 & 3.321 & $* * *$ \\
\hline Accessibility factor $I^{b}$ & $-\mathrm{S}$ & -0.291 & -7.644 & $* * *$ & NA & NA & NA \\
\hline Accessibility factor $2^{c}$ & $-S$ & -0.134 & -4.494 & $* * *$ & NA & NA & NA \\
\hline Job density within activity space polygon & $-S$ & NA & NA & NA & -0.001 & -2.996 & $* * *$ \\
\hline Percentage of limited access highways, \%L & $+\mathrm{S}$ & 2.570 & $1.86 \mathrm{I}$ & * & 3.440 & I.47I & \\
\hline Treeness, ${ }^{\mathrm{a}} \phi_{\text {tree }}$ & $-S$ & -0.270 & -0.143 & & -0.277 & -0.279 & \\
\hline Percentage of 4-degree nodes, $\% \mathrm{~N}^{4}$ & $+\mathrm{S}$ & 1.250 & 2.769 & $* * *$ & -3.260 & -3.880 & $* * *$ \\
\hline P2A $\left(\mathrm{km}^{-1}\right)$ & $-S$ & -0.086 & -6.044 & $* * *$ & -0.138 & -8.263 & $* * *$ \\
\hline Street density, $\rho_{l a}\left(\mathrm{~km}^{-1}\right)$ & $-S$ & 0.072 & -5.280 & $* * *$ & -0.033 & -3.714 & $* * *$ \\
\hline Activity space compactness, $C$ & $+\mathrm{S}$ & 2.790 & $13.7 \mid 4$ & $* * *$ & 3.120 & 12.870 & $* * *$ \\
\hline Constant & & 4.100 & 9.069 & $* * *$ & 5.580 & 9.061 & $* * *$ \\
\hline Number of observations & & 1998 & & & 663 & & \\
\hline$R$-squared & & 0.533 & & & 0.493 & & \\
\hline Adj. R-squared & & 0.530 & & & 0.484 & & \\
\hline
\end{tabular}

Notes:

* $\mathrm{p}<0.10$, ** $\mathrm{p}<0.05, * * * \mathrm{p}<0.01$.

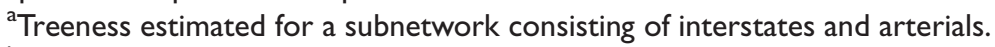

${ }^{b}$ Accessibility factor I consists primarily of the accessibility to jobs, labour and shops by auto.

${ }^{\mathrm{c}}$ Accessibility factor 2 consists primarily of the accessibility to jobs, labour and shops by transit; accessibility to shops by walk.

${ }^{\mathrm{d}}$ Compared with low-income households.

direction of the long blocks and decreasing the compactness. Another explanation could be that dense streets are associated with the inner city, which is typically associated with fewer vehicle trips because of the demographics or mode choices. Fewer trips are associated with elongation, i.e. one trip is just a line segment and therefore maximally elongated.

While the percentage of 4-degree nodes is not significant for the Twin Cities, it is negatively associated with activity space compactness, which contradicts the hypothesis in the South Florida model. A possible explanation, i.e. the close proximity of $\mathrm{CBDs}$ to the ocean for South Florida, was provided above (see also Figure 2).

The second part of Table 9 shows that the activity space compactness has a positive and highly significant influence on the size of the activity space in both study areas. The other independent network variables perform similar to the results presented in Tables 7 and 8 and are in line with our hypotheses.

Examining the control variables, it can be observed that both accessibility factors have the expected negative influence on the household activity space in the Twin Cities and are highly significant. Similarly the job density within the service area polygon also has a negative influence on the household activity space in the South Florida model. Other household level sociodemographic variables perform as expected. The number of workers in the household increases the household activity space. This is expected because households select their residential 


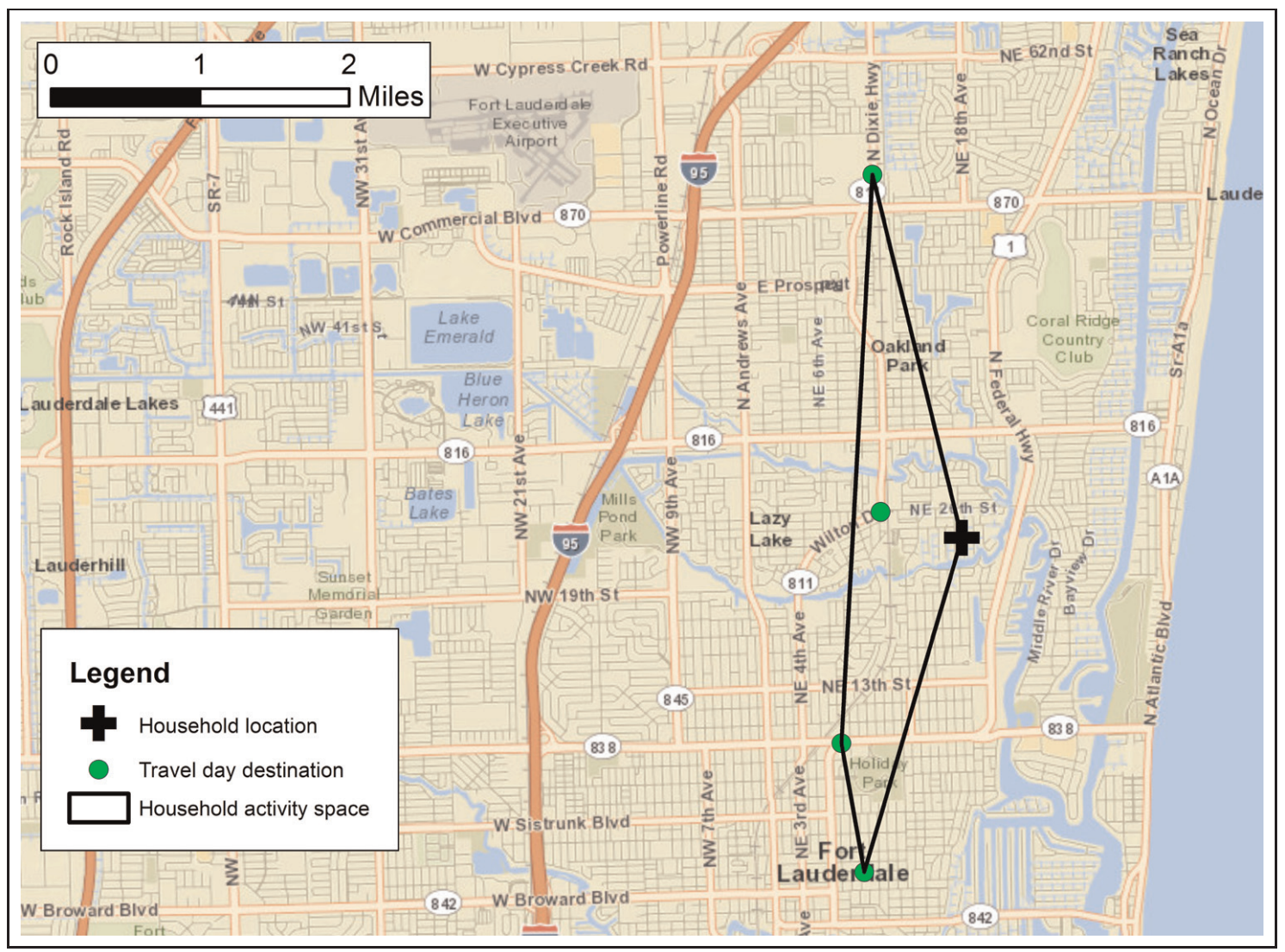

Figure 2. Identified activity space polygon for a household in Fort Lauderdale.

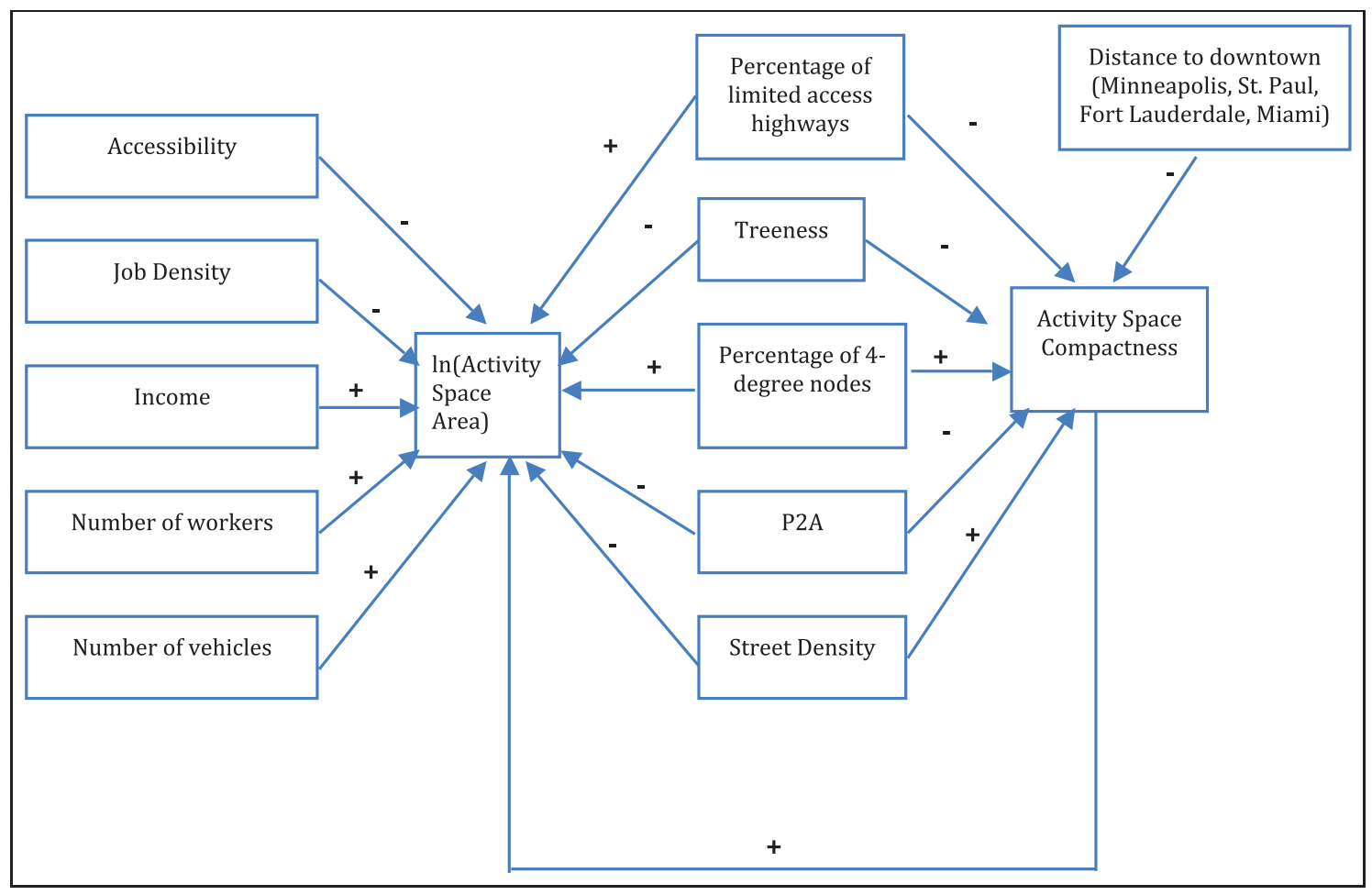

Figure 3. Path diagram showing hypothesised causal relationships. 


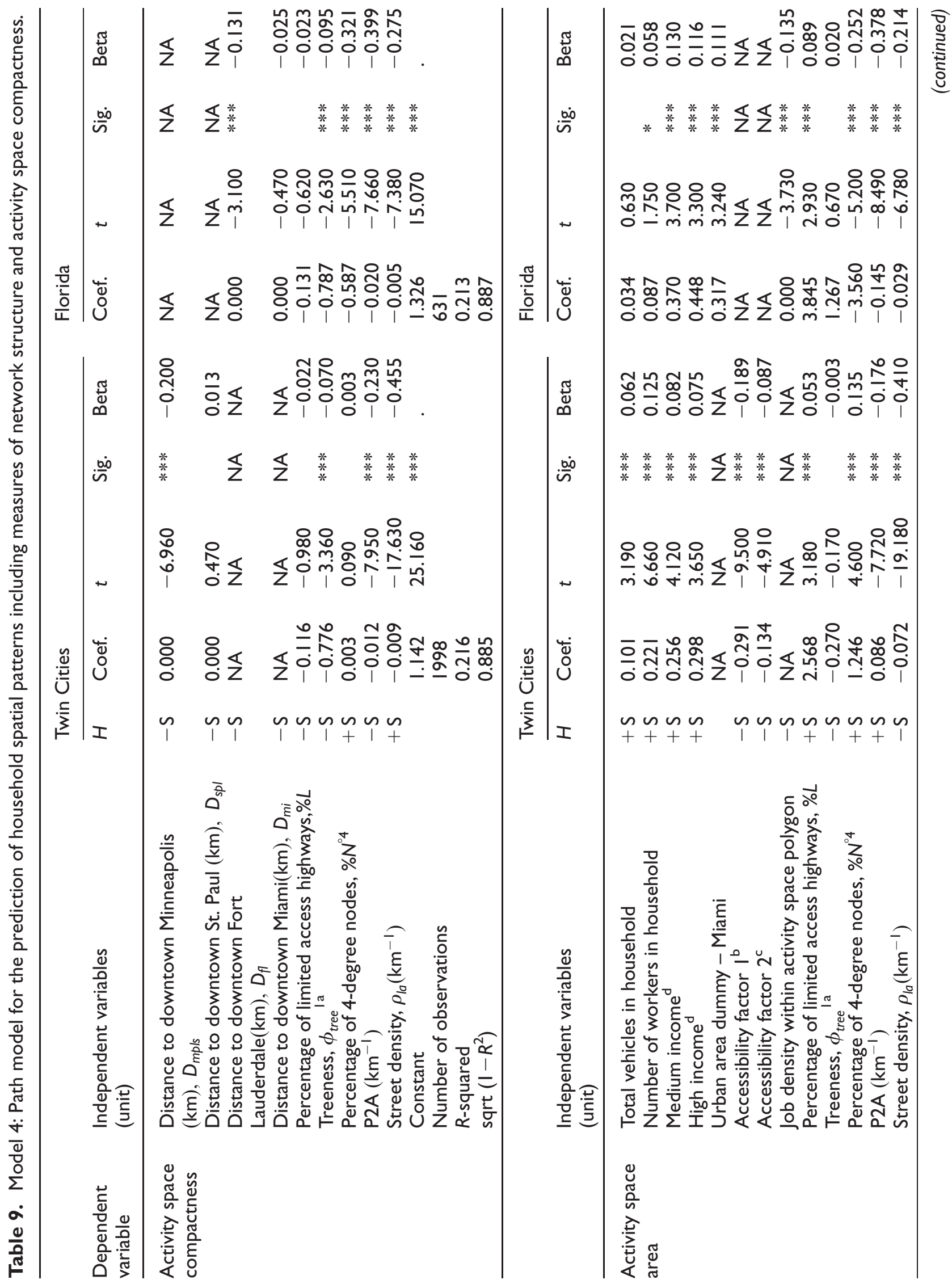




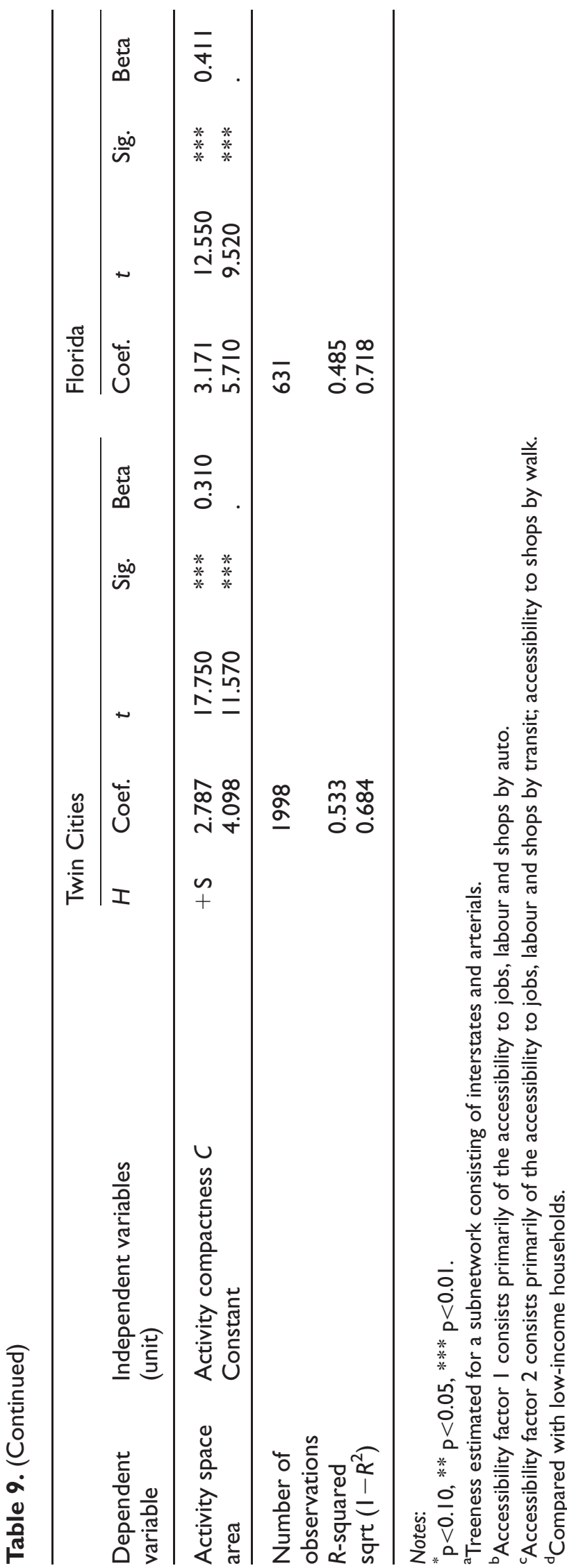

location by balancing the travel requirements of multiple workers, compared with single-worker households, among other factors. The income variables show that medium- and high-income households have a larger activity space compared with lowincome households, which corroborates the existing literature on travel behaviour. The total vehicles in the household have a positive influence in both study areas but is significant only in the Twin Cities model. This variation in the influence points to the differences in socio-demographics between the two study areas. Further this also highlights the need to control for these sociodemographic differences for a better understanding of the influence of network measures.

Since autocorrelation can affect standard errors of estimated regression coefficients, Moran's I statistic was used to test for spatial autocorrelation in residuals of the path analysis model. Results did not reveal significant spatial autocorrelation $(p>0.10)$ in either of the two study areas.

\section{Elasticities}

The model elasticities can be read directly from the results. For example, Table 8 shows that a unit increase in street density decreases the activity space by $7.2 \%$ in the Twin Cities and by $3.3 \%$ in Florida. Similarly a unit increase in the $\mathrm{P} 2 \mathrm{~A}$ of the network within the activity space decreases the household activity space by $8.6 \%$ and $13.8 \%$ for the Twin Cities and South Florida, respectively. The elasticity estimates illustrate the magnitude of influence of each of these network measures.

\section{Discussion and conclusions}

This research aimed to understand the relationship between the measures of street network structure and the household spatial 
range, using travel survey data from two study areas, namely the Twin Cities and South Florida.

The use of different models allowed us to test various combinations of the independent network measures. The difference in the magnitude of influence combined with the variation in the influence of the network variables highlights the importance of separating out the two study areas. For example, the percentage of limited access highways is significant in the Twin Cities model presented in Table 8 but insignificant in South Florida. Similarly the treeness variable showed a significant influence in the South Florida model (Table 7) but no significant influence in the Twin Cities. Additional comparisons across other areas could provide a more solid picture of the relationship between transportation network structure and activity space.

What are the implications of this research and how can the results be applied? The results quantify the influence of street network structure on household spatial patterns and explain how the design of transportation network affects travel. One could argue that this understanding is not necessarily critical since the transportation system in the USA is already in a mature stage and the focus is more on maintaining the existing infrastructure. However, a look at rapidly developing countries shows that there is a need to understand the influence of network structure.

A recent article comparing the highway systems in the USA and China, showed that in the year 2011, the total length of the Chinese highway system exceeded that of the American interstate system. What stands out in this comparison is not just the total length of the highway systems but rather the rapid rate at which this has been accomplished in China. According to reports, China added $11,000 \mathrm{~km}$ of new highways in 2012 alone
(Cox, 2013). Even more remarkable is that, prior to 1998, China did not have a highway system and the investment in transportation infrastructure was driven by the growing economy (Rodrigue, 2012). China is just one example of such rapid urbanisation and other countries in Asia and Africa are showing similar growth patterns.

In that context, proper design of transportation infrastructure can help mitigate the negative effects of rapid growth and to ensure an efficient and sustainable transportation system that can meet the growing travel demand. It is well established that the transportation sector is the biggest consumer of energy and one of the biggest sources of greenhouse gas (GHG) emissions (United State Environmental Protection Agency, 2013). Hence it is critical that network architecture is considered in the design of urban form and sustainable environments, and that transportation network decisions, which are in many ways irreversible, be well understood. Lessons learned from mature systems such as the USA and other developed countries can thus provide guidance on network design to minimise environmental impacts.

\section{Funding}

This research received no specific grant from any funding agency in the public, commercial, or notfor-profit sectors.

\section{References}

Anderson P, Levinson D and Parthasarathi P (2013) Accessibility futures. Transactions in GIS 17(5): 683-705.

Cerda A and El-Geneidy A (2009) Understanding the relationships between regional accessibility travel behaviour and home values. In: 89th Annual Meeting of the Transportation Research Board. Washington, DC: Transportation Research Board. 
Cox W (2013). China Freeways: Continuing Expansion. Available at: http://www.newgeo graphy.com/content/003378-china-freewayscontinuing-expansion (accessed 22 February 2014).

Daganzo CF (2010) Structure of competitive transit networks. Transportation Research Part B: Methodological 44(4): 434-446.

de Smith M, Goodchild M and Longley P (2007) Geospatial Analysis: A Comprehensive Guide to Principles, Techniques and Software Tools. Troubador Publishing.

Dijst M (1999) Two-earner families and their action spaces: A case study of two dutch communities. GeoJournal 48(3): 195-206.

El-Geneidy A and Levinson DM (2006). Access to Destinations: Development of Accessibility Measures. St. Paul, MN: Minnesota Department of Transportation, Research Services Section. Available through the National Technical Information Service, Springfield, VA. Report 1 in the series: Access to Destinations Study.

Erath A, Löchl M and Axhausen K (2009) Graph-theoretical analysis of the Swiss road and railway networks over time. Networks and Spatial Economics 9(3): 379-400.

Fan Y and Khattak A (2008) Urban form, individual spatial footprints, and travel: Examination of space-use behavior. Transportation Research Record: Journal of the Transportation Research Board 2082: 98-106.

Florida Department of Transportation (1999) Southeast Florida Travel Survey. Available at: http://www.fsutmsonline.net.

Garrison WL and Marble DF (1961) The structure of transportation networks. Evanston, IL: Transportation Center at Northwestern University. Draft of a report submitted 31 October 1961 to U.S. Army Transportation Research Command, Fort Eustis, Virginia, by the Transportation Center at Northwestern University under contract DA-44-177-TC-685, Transportation geography study.

Gastner M and Newman M (2006) The spatial structure of networks. The European Physical Journal B-Condensed Matter and Complex Systems 49(2): 247-252.

Gauthier HL (1966) Highway development and urban growth in Sao Paulo, Brazil: A network analysis. Ph.D. Thesis, Northwestern University.

Hägerstrand T (1970) What about people in regional science? Papers in Regional Science 24(1): 6-21.

Haggett P and Chorley R (1969) Network Analysis in Geography. London: Edward Arnold.

Harding C, Patterson Z and Miranda-Moreno L (2013) Activity space geometry and its effect on mode choice. In: 92nd Annual Meeting of the Transportation Research Board. 13-17 January 2013, Washington, DC.

Hochmair HH (2013) Assessment of bicycle service areas around transit stations. International Journal of Sustainable Transportation DOI:10.1080/15568318.2012.719998.

Horton F and Reynolds D (1971) Effects of urban spatial structure on individual behavior. Economic Geography 47(1): 36-48.

Jacques C, Manaugh $\mathrm{K}$ and El-Geneidy AM (2013) Rescuing the captive [mode] user: An alternative approach to transport market segmentation. Transportation 40(3): 625-645.

Jenelius E (2009) Network structure and travel patterns: Explaining the geographical disparities of road network vulnerability. Journal of Transport Geography 17(3): 234-244.

Jiang B (2007) A topological pattern of urban street networks: Universality and peculiarity. Physica A: Statistical Mechanics and its Applications 384(2): 647-655.

Johnston R (1972) Activity spaces and residential preferences: Some tests of the hypothesis of sectoral mental maps. Economic Geography 48(2): 199-211.

Kansky K (1963) Structure of transportation networks: Relationships between network geometry and regional characteristics. Ph.D. thesis, University of Chicago, Research Paper No. 84.

Kissling C (1969) Linkage importance in a regional highway network. The Canadian Geographer 13(2): 113-127.

Kwan M-P (2000) Gender differences in spacetime constraints. Area 32(2): 145-156.

Leclair SW (1981) Path analysis: An informal introduction. The Personnel and Guidance Journal 59(10): 643-646.

Levinson D (2012) Network structure and city size. PloS ONE 7(1): e29721. 
Levinson D and El-Geneidy A (2009) The minimum circuity frontier and the journey to work. Regional Science and Urban Economics 39(6): 732-738.

Levinson D, Marion B and Iacono M (2010) Access to destinations, Phase 3: Measuring accessibility by automobile. Final Report MN/ RC 2010-09, Minnesota Department of Transportation Research Services Section. Available through the National Technical Information Services, Springfield, Virginia 22161, at: http:// www.lrrb.org/PDF/201009.pdf.

Lleras C (2005) Path analysis. Encyclopedia of Social Measurement 3: 25-30.

Marshall S (2005). Streets \& Patterns. New York: Spon Press.

Marshall W and Garrick N (2010) Street network types and road safety: A study of 24 California cities. Urban Design International 15: 133-147.

Metropolitan Council (2003) 2000 Travel Behavior Inventory Home Interview Survey: Data and Methodology. St. Paul, MN: Metropolitan Council.

Miller HJ (2005) A measurement theory for time geography. Geographical Analysis 37(1): $17-45$.

Newsome T, Walcott W and Smith P (1998) Urban activity spaces: Illustrations and application of a conceptual model for integrating the time and space dimensions. Transportation 25(4): 357-377.

Nexus Research Group (2008) Metropolitan Travel Survey Archive. Available at: http:// www.surveyarchive.org/.

Owen A and Levinson D (2012) Access to destinations: Annual accessibility measure for the twin cities metropolitan area. Final Report MN/RC 2012-34, Minnesota Department of Transportation Resesearch Services Section. Report no.13 in the series Access to Destinations Study; Available through the National Technical Information Services, Alexandria, Virginia 22312, at: http://www.lrrb.org/pdf/201234.pdf.

Parthasarathi P, Hochmair $\mathrm{H}$ and Levinson D (2012) Network structure and spatial separation. Environment and Planning B, Planning and Design 39(1): 137-154.

Parthasarathi P, Levinson D and Hochmair H (2013) Network structure and travel time perception. PloS ONE 8(10): e77718.
Patuelli R, Reggiani A, Nijkamp P, et al. (2010) The evolution of the commuting network in Germany: Spatial and connectivity patterns. Journal of Transport and Land Use 2(3/4): 5-37.

Rodrigue J (2012) Length of the Interstate Highway System and of the Chinese Expressway System, 1959-2012 (in km). The Geography of Transport Systems. Available at: http://peo ple.hofstra.edu/geotrans/eng/ch3en/conc3en/ interstatemileage.html (accessed 22 February 2014).

Rodrigue J, Comtois C and Slack B (2006) The Geography of Transport Systems. London, New York: Routledge.

Schönfelder S and Axhausen K (2003) Activity spaces: Measures of social exclusion? Transport Policy 10(4): 273-286.

Schönfelder S and Axhausen K (2004) Structure and innovation of human activity spaces. Arbeitsberichte Verkehrs-und Raumplanung 258, Zürich: IVT, ETH Zürich.

Schrank D, Eisele B and Lomax T (2012) 2012 Urban Mobility Report. Texas Transportation Institute, The Texas A\&M University System.

Sherman J, Spencer J, Preisser J, et al. (2005) A suite of methods for representing activity space in a healthcare accessibility study. International Journal of Health Geographics 4(1): 24.

Smith MS and Kauermann G (2011) Bicycle commuting in melbourne during the 2000s energy crisis: A semiparametric analysis of intraday volumes. Transportation Research Part B: Methodological 45(10): 1846-1862.

Stopher P and Wargelin L (2010) Conducting a household travel survey with gps: Reports on a pilot study. In: 12th World Conference on Transport Research. 11-15 July 2010, Lisbon.

Swanson K (2012) Bicycling and Walking in the United States: 2012 Benchmarking Report. The Library of Congress, United States Copyright Office, Washington, DC: Alliance for Biking \& Walking.

Taaffe E, Gauthier H and Morton E (1996) Geography of Transportation. Upper Saddle River, NJ: Prentice-Hall.

Timmermans H and Zhang J (2009) Modeling household activity travel behavior: Examples of state of the art modeling approaches and 
research agenda. Transportation Research Part B: Methodological 43(2): 187-190.

United States Environmental Protection Agency (2013) Transportation and Climate. Available at: http://www.epa.gov/otaq/climate/basicinfo.htm (accessed 22 February 2014).

Urry J (2003) Social networks, travel and talk 1. The British Journal of Sociology 54(2): 155-175.

US Census Bureau (2008) Topologically Integrated Geographic Encoding and Referencing System (TIGER) Overview. Available at: http://www.census.gov/geo/maps-data/data/tigerline.html (accessed 4 July 2009).

US Census Bureau (2010) American Community Survey, 2010. Available at: http://mcdc2.mis souri.edu/cgi-bin/uexplore?/pub/data/acs2010.

Vallée J, Cadot E, Grillo F, et al. (2010) The combined effects of activity space and neighbourhood of residence on participation in preventive health-care activities: The case of cervical screening in the Paris metropolitan area (France). Health \& Place 16(5): 838-852.

Wright S (1934) The method of path coefficients. The Annals of Mathematical Statistics 5(3): 161-215.

Xie F (2007) Simulator Of Ultra-connected Network Degeneration (SOUND): Identifying Network Topologies. Code available at: http:// nexus.umn.edu/Software/IdentifyingNetwork Topologies.zip.

Xie F and Levinson D (2007) Measuring the structure of road networks. Geographical Analysis 39(3): 336-356.

Xie F and Levinson D (2011) Evolving Transportation Networks. New York, NY: Springer.

Yang C, Tu Y and Chen X (2009) Analysis method for topology vulnerability of transportation network. In: Peng Q, Wang KCP and Qiu Y (eds) Proceedings of the Second International Conference on Transportation Engineering. Reston, VA: ASCE, pp. 3639-3644. 